\title{
Software Application Teaching Combined With Computational Thinking
}

\author{
Li Jiang, Guohua Zhan, Zhihua Li \\ Hangzhou Institute of Service Engineering \\ Hangzhou Normal University \\ Hangzhou, China \\ 18368104801@163.com,ghzhan@hznu.edu.cn, zhihuali_e@163.com
}

\begin{abstract}
The cultivation and training of computational thinking become more and more significant in basic computer education in university. In this paper, firstly the necessity of the computational thinking is analyzed in contribution to the learning of the usage of application software. And then a new teaching scheme based on computational thinking is proposed in the computer teaching design and teaching pattern. The experimental results show that the application software teaching based on computational thinking is feasible and more effective to improve the quality of our teaching
\end{abstract}

Keywords-Computational Thinking; Basic Computer Education; Teaching Design

\section{BACKGROUND}

Computational thinking is proposed by Jeannette $\mathrm{M}$. Wing. Computer basic education focus on the combination of cultivate and training of computational thinking and using the application software with the specific function. Computational thinking is a newly presented in the past few years. In recent years, with the rapid development of information technology and computer teaching, application software is more and more important in our work and life. We realized that computational thinking is not only for computer scientists, but also a fundamental skill for everyone.

Jeannette M.Wing publish the <Computational Thinking $>$ in Communications of the ACM[1], a international famous computer magazine. Computation thinking is make use of computer science's basic conception to solve problems, design system and understands human behavior, which cover a series of conceptual work in computer science field.

But, it is difficult to give computational thinking a exact connotation definition. We can put more effort on applying computational thinking to make scientific discovery and technological innovation in other science field. Before building computational thinking, we want to make everyone understand the teaching purpose of computational thinking. The true meaning of computational thinking is training a thinking habit, how to understand problem and get solution as the computer scientist's way of thinking. With the development of computational thinking, it is enriched by Chen and Dong, adding abstraction in it [2].

\section{INTRODUCTION}

With the development of Internet, applications are becoming an important tool in our life and work. No matter who can avoid operating application software? In addition, subjects in teaching usage of application software accounts for a high percentage in computer basic education in university. Students can learn lots of knowledge of technology about them.

In our teaching progress, what we concentrate on is tool's usage and just split function parallel, which is not very suitable and understandable for beginners. For example, Microsoft Office is very excellent and widely used in school and company, but we cannot teach all usages of it. Learner need to comprehend software's design and operate it. [6] From existing teaching structure, we do not provide system comprehensive thinking to students. So, we find some problems in our teaching process. First, whether our teaching is cramming method of teaching. Second, whether we mobilize student's brain into operation. Third, what we give students is not just simple operation on some specific software, but rather a thinking habit in operating new software that he never learned it.

We can review the meaning of computational thinking, which give us lots of inspire in learning operating software system.

From the aspect of study, to solve a problem, we should confirm our thinking logically:

(1). We should state problem in a concise way, understand the key of the problem and know benefits of the solution.

(2). We should try to divide a big problem into some parts. Then we just need to solve every part, and combine our solution.

(3). We may find different kinds of solution, but how to select the best one is also a trouble for us. Thus, it is necessary for us to adjust and test every solution, which can be comparing with each other.

From the aspect of technology, we can choose an abstraction side to think about information technology. If you do that, you may ask some questions:

- What function should I grasp, if I need to complete my task? 
- The designer and developer want users operate the software correctly as their design thinking. However, how can we know developers' design idea and do that in a right way?

- What information and thinking habit does the design idea of software reflect?

- Whether the function of software designed can satisfy our task's requirement?

- Whether there are some similarities between two software, and we can pick up software operation more quickly.

When we look back our existing teaching method, we can get understand that what we lack is training correct thinking habit and ability of ask question like the above. In this paper, we consider that we can change some teaching method to solve the problem.

\section{ANALYSIS OF TEACHING METHOD}

A. The past method of teaching basic software application.

Basic computer education in university have maintained a relative long time. However, with the development of internet and concentration of computational thinking, some disadvantages is more and more obvious. I research some textbooks about university's basic computer education. Their sequences of teaching usage of software are similar. And their content cannot attract students to have deeper thinking about software. What they focus on is just some specific cases and exact operations. They do not explain to students the reason why he should do that. In the process of teaching, students just imitate teacher's action and lose the purpose of learning computer.

For example, Microsoft Office Word is a office automatic software widely used. What we introduce firstly is summarize of MS Office and Word2010. We can find it from Img1. This chapter hopes students have general comprehension on this software and the place where it apply. From then on, next chapters just tell how to use Word2010 do some actions. These cases in book reflect some issues. First, Student is hard to understand the intent of software design. Second, these cases cannot help to grasp software's usage, because these cases are relative dependent. If learner does not understand it enough, cases may not have too effective work. From the above, each part of our teaching plan is parallel and lack of layering.

\section{B. Content of compound teaching method}

Computational thinking unconsciously exists in current teaching process. This thinking need to be organized suitable and explained reasonable in class. Before we learn it, we have to comprehend it.

Computational thinking is recursion thinking. Recursion thinking can help us solve big problem by reducing the scale of the problem increasingly [3][4]. In the other hand, computational thinking can make use of abstraction and disintegration to deal with the complex task and design the software system on a large scale. This mode of thinking can give us heuristic thinking to translate it into our teaching plan.

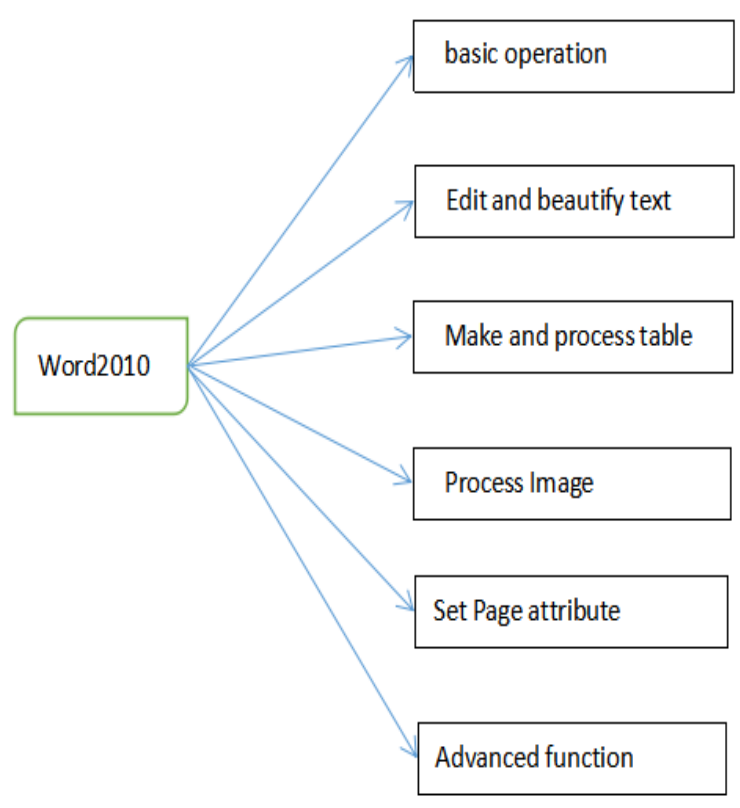

Fig 1.existing Word2010 teaching module

Application software teaching accounts for a large proportion. We propose that learners view learning process and cases they met with right thinking habit. I introduce my teaching method with computational thinking in detail in the following content.

In teaching process, we hope students are capable to make use of computational thinking deal with the problem. But I believe that teacher must grasp computation thinking habit firstly.

First of all, some questions should be asked. These questions confirm my teaching pertinence, which is important to get the key points.

(1). Why do you need to learn to use software?

(2). what task can this software complete?

(3). although the usage of software is complex, how can we get some similarities to help us training a thinking from the other software?

(4). How can we build a hierarchical model in teaching process?

In the following, we bring those questions to analyze our existing teaching and present some reform. We still use teaching the usage of MS Office and Word2010 as example to state viewpoint.

In the beginning, it is very necessary to introduce the purpose the software servers. For example, Word2010 as 
word processor is efficient and friendly interface. This word processor helps us save time and provide us an elegant and beautiful result. In addition, it can deal with text formatting and simple image processor. From that information, we can know that Word 2010 have lots of advantages and we realize that if we need to complete our task about text processor, we will choose Word2010. The beginner has realized the purpose and has a general view of it. In the next, we will explain to the beginners some knowledge points in comparison.

As we all know, Notepad is also a text processor application in computer. And Notepad is a light weight text processor application compare with MS Office Word 2010. The numbers of function in Notepad is less than that in Word2010. But we can get many similarities between Notepad and Word2010. By analyzing these similarities, we will construct the design framework, which will help learners have more understanding.

We find that both Notepad and Word2010, their layout and manuscript is alike. Their menu gives us guidance. Word2010 have a blank page, which contains our content such as words, images. Its menu have so many button, we divide those buttons into six types (Fig 2).

- adding a new object into text, such as words, images or special objects.

- editing existed content. For example, give your paragraph a style, your paragraph will represent neat and orderly. If you want to emphasize key words, you can highlight them.

- locating and replacing your content. If you need to replace some words, you can use this function to finish your task quickly, exactly and efficiently. You can give some index for your chapter so that you can know text's structure and locating it.

- multi-people operate one text file. In order to deal with the problem in Collaboration work, Word2010 provide review menu.

- advanced function provided. This part has lots of tools, which is used to satisfy some special requirement. Such as counting the number of words.

The sixth type is complex and includes many special functions.

In teaching process, we need to transfer this thinking to students. Then we explain the reason why we do that.

In order to help students learning the usage of software, we usually ask them finish some cases to build their degree of proficiency. However, I think that different cases should be useful for students to understand different type of software menu.

In the past, we just teach students operate software to finish cases. In this process, students do not build their own thinking method. What they need to do is following teacher's action. However, when we import computational thinking, in fact, students may need to consider and look for right action by themselves. It is good for students to build their thinking habit.

If students have a problem to finish, first, they need to locate the problem. Then, to find out the solution, they should consider the purpose of task and determine the action type. At last, they find right function menu and choose function to deal with their task.

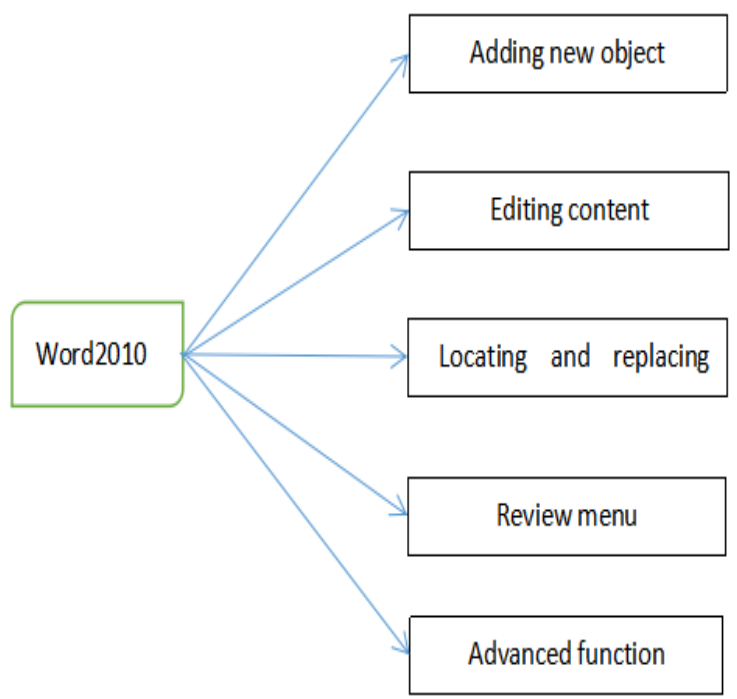

Fig 2. optimized Word2010 teaching module

We believe that if learner has trained this thinking habit, they may understand the software design thinking and make them learn other software operation more quickly and have ability to deal with different kinds task by tools.

\section{CONCLUSION}

In this paper, we propose a better teaching method of software applying. We compare our new teaching with existed one and evaluate our new teaching method from three aspects.

I). Innovation

In this teaching plan, I combine computational thinking with the existed. It is a fresh idea in teaching area. The existed teaching just focuses on simple operation, which can not help students have self-thought and improve their real practice ability.

II).Practicable

As an innovation idea, we must discuss its practicable. In fact, our new idea makes teacher and students have more clear aim and give students more autonomy. Under this teaching method, learning becomes more interesting and understandable.

III).Effectiveness 
This teaching method imports the advantage of computational thinking and save the good of existed method. So, there is no doubt that it is better than existed one. It not only helps students use a kind of software, but also train their thinking habit and teach them the method of other kinds of software.

In conclusion, the compound teaching method is innovation, practicable and effectiveness. It can improve teaching quality and realize make use of computational thinking to deal with problems in teaching.

\section{RELATED WORK}

In researching computation thinking, Jeannette M.Wing publish the $<$ Computational Thinking $>[1]$. In that paper, she gives us a new thinking. I make use of this thinking method to solve many practical problems. From basic computer education research, we see the practice in education field with computational thinking, which provide us an inspiration to apply this thinking to software application.

In the future, we try to improve our work on teaching software application. We also meet some difficult. For example, when we consider that how to evaluate students' level of computational thinking. Because the proficiency of special software may not reflect the real ability of students. Whether we should teach students learn software operation from the aspect of developers' design .Those problem should be paying more efforts.

\section{REFERENCE}

[1] Jeannette M.Wing. Computational Thinking[J].2006 .

[2] http://d.wanfangdata.com.cn/Periodical/zgdxjx201312007(in

\section{Chinese)}

[3] Run Zhang,Junsheng Yang. Basic Computer Teaching Research and Practice in Universities Based on Computational Thinking, Computer Science and Electronic Technology International Society TP3-4;G642

[4] Zhenyu Yang; Yushui Geng; Xinggang Wang. The Research and Innovation of University Computer Basic Teaching, Proceedings of 2013 International Conference on Education and Teaching(ICET 2013) Volume 22

[5] Olga Mironova; Irina Amitan; Jüri; Vilipōold.Computational Thinking and Flexible Learning:Experience of Tallinn University of Technology; Lecture Notes in Information Technology-Proceedings of 2012 2nd International Conference on Future Computers in Education(ICFCE 2012)

[6] Konstantin Aksyonov; Eugene Bykov; Olga Aksyonova. Development of Simulation-based Software Design Solution 201405-31 